\title{
The Effects of Web Opening on Web Crippling Strength of Cold-Formed Steel Channels under Interior-Two-Flange Loading Condition
}

\author{
Asraf Uzzaman; David Nash; Jim Rhodes \\ Department of Mechanical and Aerospace Engineering \\ The University of Strathclyde, 75 Montrose Street, Glasgow G1 1XJ, UK \\ asraf.uzzaman@strath.ac.uk; d.nash@strath.ac.uk; jim.rhodes@strath.ac.uk \\ James B.P. Lim \\ School of Planning, Architecture and Civil Engineering \\ Queen's University Belfast, Belfast BT9 5AG, UK \\ j.lim@qub.ac.uk \\ Ben Young \\ Department of Civil Engineering \\ The University of Hong Kong, Pokfulam Road, Hong Kong \\ young@hku.hk
}

\begin{abstract}
Cold-formed steel sections are increasingly used in residential and commercial construction as both the primary as well as the secondary framing members. Web crippling at points of concentrated load or reaction is well known to be a significant problem, particularly in thin walled beams. To improve the buildability of buildings composed of cold-formed steel channel-sections, openings in the web are often required, for ease of installation of electrical or plumbing services. In this paper, a combination of experimental tests and non-linear elasto-plastic finite element analyses are used to investigate the effect of such holes on web crippling under the interior-two-flange (ITF) loading condition. In the case of the tests with web openings, the web holes located at the mid-depth of the webs. A non-linear elasto-plastic finite element model is described, and the results compared against the laboratory test results; a good agreement was obtained in terms of both strength and failure modes.
\end{abstract}

\section{Introduction}

Cold-formed steel sections are often used as wall studs or floor joists; such sections often include web holes for ease of installation of the electrical or plumbing services. These holes are usually pre-punched in the factory. Web crushing or crippling at points of concentrated, or localized, load or reaction in thin walled beams is well-known to be a significant problem, particularly in the case of beams with slender webs, and is of high importance in the field of cold-formed steel members, as such members are generally not stiffened against this type of loading. At points of concentrated loading and supports, severe lateral loading can result in local buckling in the web (Rhodes and Nash, 1998). For sections with holes, such web crippling needs to be taken into account.

There has been little research on the web crippling of cold-formed steel sections with web holes. Yu and Davis (1973) described 20 tests investigating the web crippling strength of

Proc. of the $10^{\text {th }}$ Intl. Conf. on Advances in Steel Concrete Composite and Hybrid Structures

Edited by J Y Richard Liew and Siew Chin Lee

Copyright (C) 2012 Research Publishing Services. All rights reserved.

ISBN: 978-981-07-2615-7:: doi:10.3850/978-981-07-2615-7_079 
Proc. $\mathrm{C}$

back-to-back channel sections with an interior-one-flange (IOF) loading condition. The test programme comprised both circular and square holes; the holes were located and centered beneath the bearing plate. Strength reduction factors were proposed. Sivakumaran and Zielonka (1989) described 103 tests on single lipped channel sections, but again for the IOF loading condition and with the circular holes located and centered beneath the bearing plate. Again, strength reduction factors were proposed. LaBoube et al. (1999) described 168 tests on single lipped channel sections, covering both IOF and end-one-flange (EOF) loading conditions but with the circular holes positioned offset, next to the bearing plate. Strength reduction factors were again proposed. Similar tests were also described by Langan et al. (1994), but with rectangular holes. Lagan et al. (1994) demonstrated that the main factors influencing the web crippling strength are the ratio of the hole depth to the depth of the web, and the ratio of the distance from the edge of the bearing to the flat depth of web. More recently, Zhou and Young (2010) conducted 84 tests on aluminum alloy square hollow sections with circular holes located and centered beneath the bearing plates. The web crippling tests were conducted under loading conditions of end-two-flange (ETF) and interior-two-flange (ITF). Reduction factor equations were also proposed.

Most design specifications for cold-formed steel structural members provide design rules for cold-formed steel channel sections without web holes; only in the case of the North American specification for cold-formed steel sections (AISI, 2007) are reduction factors for web crippling with holes presented, covering the cases of IOF and EOF, and with the flanges of the sections unfastened to the support. The holes are assumed to be located at the mid-height of the specimen having a longitudinal clear offset distance between the edge of the bearing plates and the web hole.

In this paper, a combination of experimental tests and non-linear elasto-plastic finite element analyses (FEA) are used to investigate the effect of offset circular web holes on the web crippling strength of lipped channel sections for the ITF loading condition, as shown in Fig. 1. The general purpose FE program ANSYS (2011) was used for the numerical investigation. A good agreement between the experimental tests and FEA was obtained.

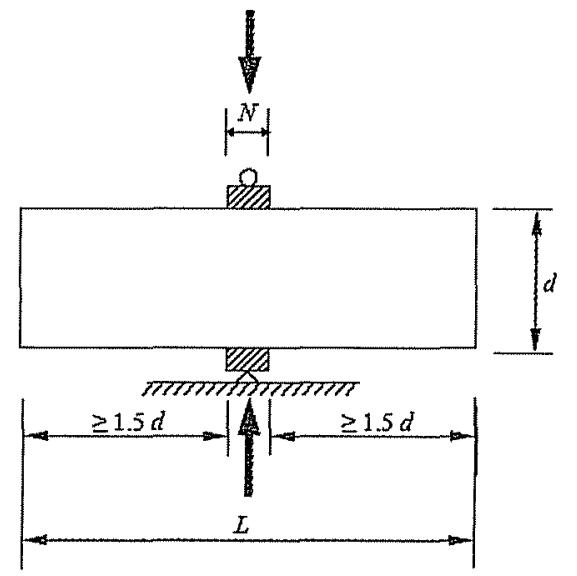

(a) Without holes

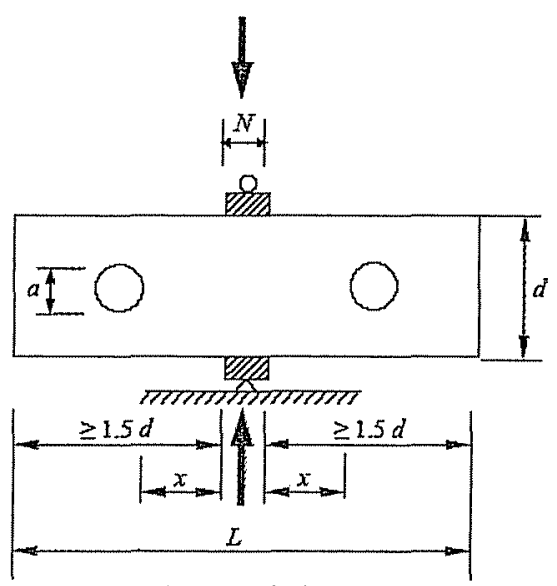

(b) With holes

Figure 1: ITF loading condition

\section{Experiment Investigation}

\subsection{Test Specimens}

A test programme was conducted on lipped channel sections, as shown in Fig. 2, with circular web holes subjected to web crippling. The size of the web holes was varied in order to 
investigate the effect of the web holes on the web crippling strength. The circular holes with nominal diameters (a) ranging from 40 to $240 \mathrm{~mm}$ were considered in the experimental investigation. The ratio of the diameter of the holes to the depth of the flat portion of the webs $(a / h)$ was 0.4 . All the test specimens were fabricated with web holes located at the middepth of the webs. The horizontal clear distance of the web holes to the near edge of the bearing plate $(x)$ is shown in Fig. 1.

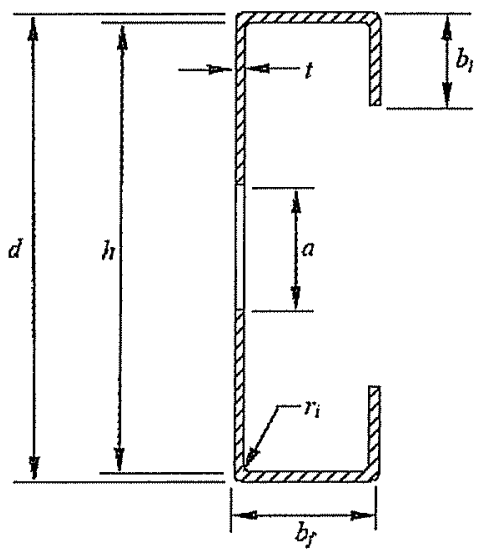

Figure 2: Definition of symbols

Channel sections without holes were also tested. The test specimens comprised five different section sizes, having the nominal thicknesses ranging from 1.3 to $2.0 \mathrm{~mm}$; the nominal depth of the webs and the flange widths ranged from 142 to $302 \mathrm{~mm}$. The measured web slenderness $(h / t)$ values of the channel sections ranged from 116 to 176 . The specimen lengths $(L)$ were determined according to the NAS Specification (2007). Generally, the distance from the edge of the bearing plate to the end of the member was set to be 1.5 times the overall depth of the web $(d)$ rather than 1.5 times the depth of the flat portion of the web (h), the latter being the minimum specified in the specifications. Table 2 shows the measured test specimen dimensions for the flange unfastened and fastened conditions, respectively, using the nomenclature defined in Fig. 1 and Fig. 2 for the ITF loading condition. The bearing plates' thickness was $25 \mathrm{~mm}$. Two lengths of bearing plates $(N)$ were used: the full flange width of the channel section and the half width of the channel section.

\subsection{Specimens Labeling}

In Table 2, the specimens were labeled such that the loading condition, the nominal dimension of the specimen and the length of the bearing as well as the ratio of the diameter of the holes to the depth of the flat portion of the webs $(a / h)$ could be identified from the label. For example, the labels "202-N32.5A0FR" defines the following specimens. The first symbol is the nominal depth of the specimens in millimeters. The notation "N32.5" indicates the length of bearing in millimeters $(32.5 \mathrm{~mm})$. The last notations " $A 0.2$ ", " $A 0.4^{\prime}$, " $A 0.6$ " and

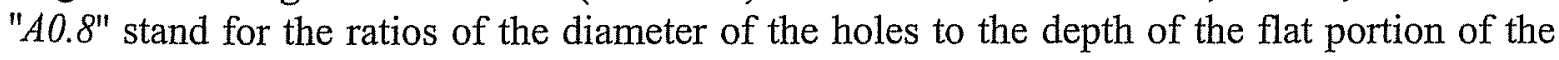
webs $(a / h)$ were $0.2,0.4,0.6$ and 0.8 , respectively. ( $A 0.2$ means $a / h=0.2 ; A 0.8$ means $a / h=$ $0: 8)$.Ten tests were conducted on the channel section specimens without web holes that are denoted by " $A 0^{\prime \prime}$.

\subsection{Material Properties}

Tensile coupon tests were carried out to determine the material properties of the channel specimens. The tensile coupons were taken from the centre of the web plate in the longitudinal direction of the untested specimens. The tensile coupons were prepared and tested according to the British Standard for Testing and Materials (2001) for the tensile 
testing of metals using $12.5 \mathrm{~mm}$ wide coupons of a gauge length $50 \mathrm{~mm}$. The coupons were tested in a MTS displacement controlled testing machine using friction grips. Two strain gauges and a calibrated extensometer of $50 \mathrm{~mm}$ gauge length were used to measure the longitudinal strain. The material properties obtained from the tensile coupon tests are summarized in Table 3 , which includes the measured static $2 \%$ proof stress $\left(\sigma_{0.2}\right)$, the static tensile strength $\left(\sigma_{u t}\right)$ and the elongation after fracture $\left(\varepsilon_{f}\right)$ based on a gauge length of $50 \mathrm{~mm}$.

Table 1: Material properties of the specimens

\begin{tabular}{|c|c|c|c|}
\hline Section & $\sigma_{0.2}(\mathbf{M P a})$ & $\sigma_{u}(\mathbf{M P a})$ & $\varepsilon_{f}(\%)$ \\
\hline $142 \times 60 \times 13 \times 1.3$ & 455 & 532 & 23 \\
\hline $172 \times 65 \times 16 \times 1.3$ & 534 & 566 & 10 \\
\hline $202 \times 65 \times 13 \times 1.4$ & 513 & 552 & 11 \\
\hline $262 \times 65 \times 13 \times 1.6$ & 525 & 546 & 10 \\
\hline $302 \times 88 \times 18 \times 2.0$ & 483 & 523 & 11 \\
\hline
\end{tabular}

\subsection{Test Rig and Procedure}

The specimens were tested under the ITF loading condition specified in the NAS Specification (2007), as shown in Fig. 3. For the ITF loading conditions, two identical bearing plates of the same width were positioned at the end and at the mid-length of each specimen, respectively. Hinge supports were simulated by two half rounds in the line of action of the force. A servo-controlled Tinius-Olsen testing machine was used to apply a concentrated compressive force to the test specimens. Displacement control was used to drive the hydraulic actuator at a constant speed of $0.05 \mathrm{~mm} / \mathrm{min}$ for all the test specimens. The load or reaction force was applied by means of the bearing plates. The bearing plates were fabricated using high strength steel. All the bearing plates were machined to specified dimensions, and the thickness was $25 \mathrm{~mm}$. The bearing plates were designed to act across the full flange widths of the channel sections.

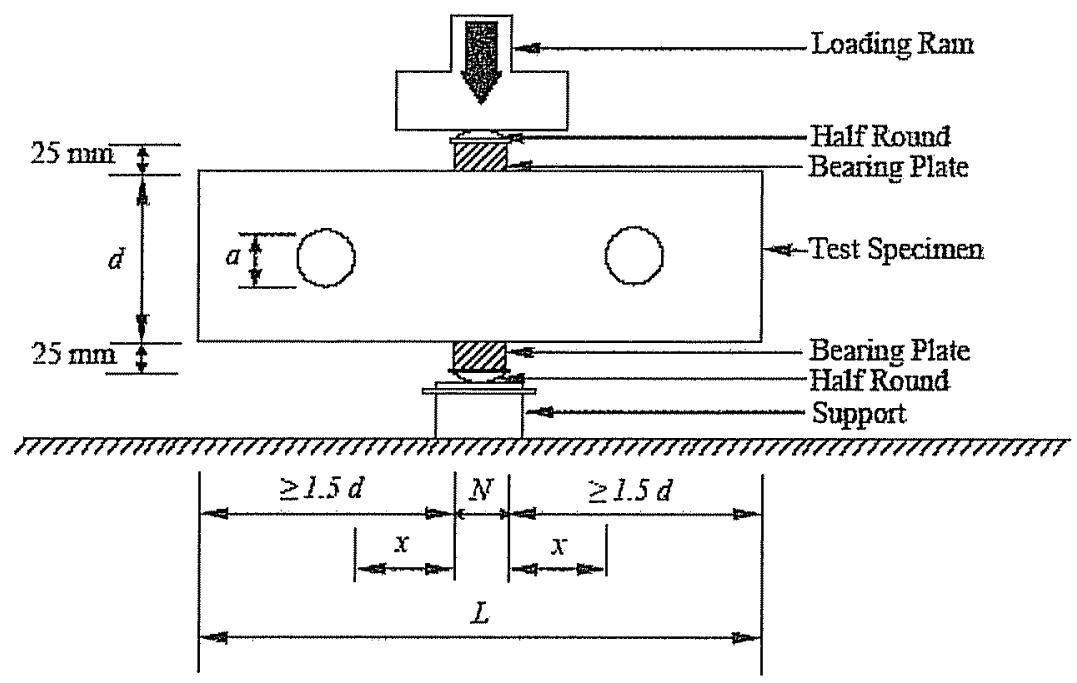

Figure 3: Definition of symbols 


\subsection{Test Results}

A total of 20 specimens were tested under the ITF loading condition. The experimental ultimate web crippling loads per web $\left(\mathrm{P}_{\mathrm{EXP}}\right)$ are given in Table 2 . The typical failure mode of web crippling of the specimens is shown in Fig. 4. A typical example of the load-defection curve obtained from a specimen both without and with web holes, and the comparisons with the numerical results is shown in Fig. 6.
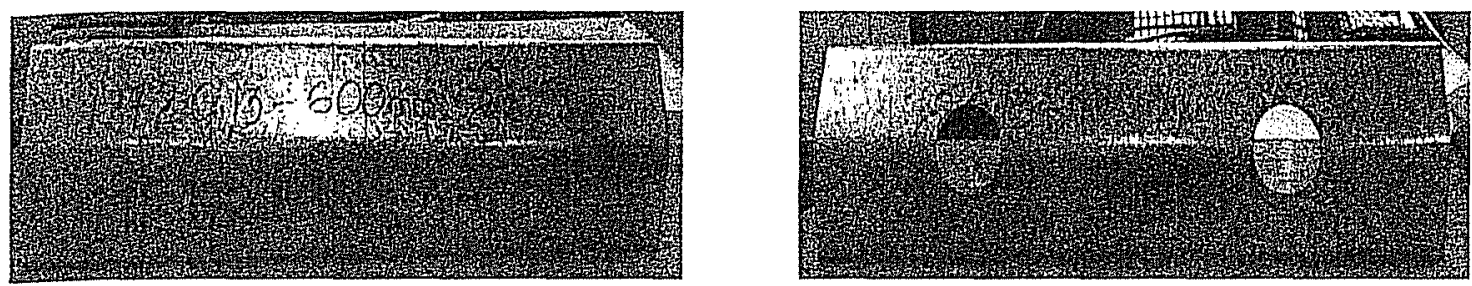

Figure 4: Typical failure mode of the specimens

\section{Numerical Investigation}

\subsection{General}

The non-linear elasto-plastic general purpose FE program ANSYS (2011) was used to simulate the channel sections with and without holes subjected to web crippling. The bearing plates, the channel section with circular holes and the interfaces between the bearing plates and the channel section have been modeled. In the FE model, the measured cross-section dimensions and the material properties obtained from the tests were used. The model was based on the centerline dimensions of the cross-sections. Specific modeling issues are described in the following subsection.

\subsection{Geometry and Material Properties}

One-quarter of the test set-up was modeled using symmetry about both the vertical transverse and horizontal planes, and is shown in Fig. 5(b). Contact surfaces are defined between the bearing plate and the cold-formed steel section. The value of Young's modulus was 203 $\mathrm{kN} / \mathrm{mm}^{2}$ and Poisson's ratio was 0.3 . The material non-linearity was incorporated in the FE model by specifying 'true' values of stresses and strains. The plasticity of the material was determined by a mathematical model, known as the incremental plasticity model; the true stress and plastic true strain were as per the specified method in the ANSYS manual (2011).

\subsection{Element Type and Mesh Sensitivity}

Fig. 5(b) shows details of a typical FE mesh of the channel section and the bearing plate. The effect of different element sizes in the cross-section of the channel section was investigated to provide both accurate results and reduced computation time. Depending on the size of the section, the FE mesh sizes ranged from $3 \times 3 \mathrm{~mm}$ (length by width) to $5 \times 5 \mathrm{~mm}$. It is necessary to finely mesh the corners of the section due to the transfer of stress from the flange to the web. Nine elements were used around the inside corner radius that forms the bend between the flange and web. Three elements were used at the rounded corners between the flange and lip of the section. The number of elements was chosen so that the aspect ratio of the elements was as close to one as possible. Where holes were modeled, finer mesh sizes were used around the web holes. Mesh sensitivity analyses were performed to verify the number of elements. The channel sections were modeled using the 4-noded shell element SHELL181. 


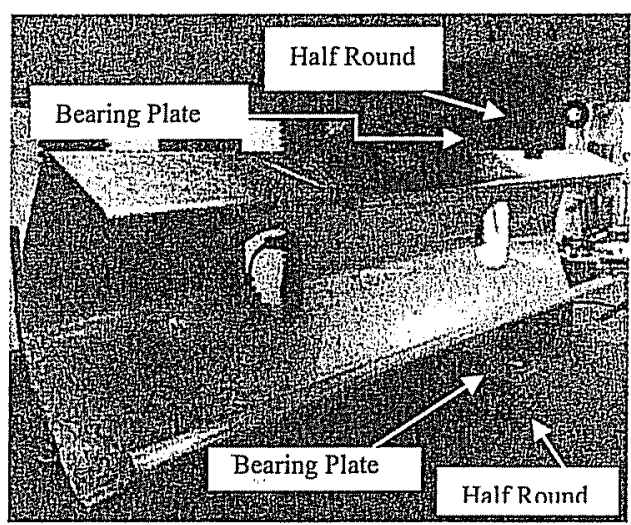

(a) Experimental

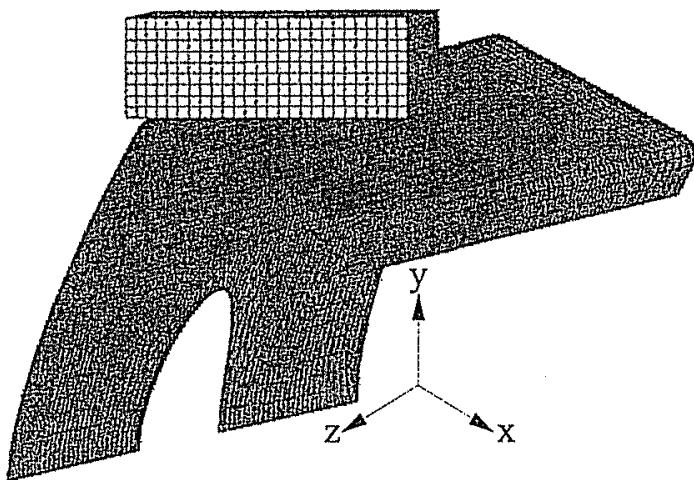

(b) FEA

Figure 5: Comparison of experiment and FEA

The bearing plates were modeled using the eight-noded solid element SOLID45. CONTAT173 and TARGET170 elements were used for modeling contact between the flanges and the load bearing plates.

\subsection{Loading and Boundary Conditions}

The nodes of the cold-formed steel section and the bearing plate were restrained to represent the vertical and horizontal symmetry condition. The interface between the bearing plate and the cold-formed steel section were modeled using the surface-to-surface contact option. The bearing plate was the target surface, while the cold-formed steel section was the contact surface. The two contact surfaces were not allowed to penetrate each other. The vertical load applied to the channel sections in the laboratory tests was modeled using displacement control method; an imposed displacement is applied to the nodes of the top bearing plate where the vertical load is applied. The top bearing plate was restrained against all degrees of freedom, except for the translational degree of freedom in the $\mathrm{Y}$ direction.

\subsection{Verification of FE Model}

In order to validate the FE model, the experimental failure loads were compared against the failure load predicted by the FEA. The main objective of this comparison was to verify and check the accuracy of the FE model.

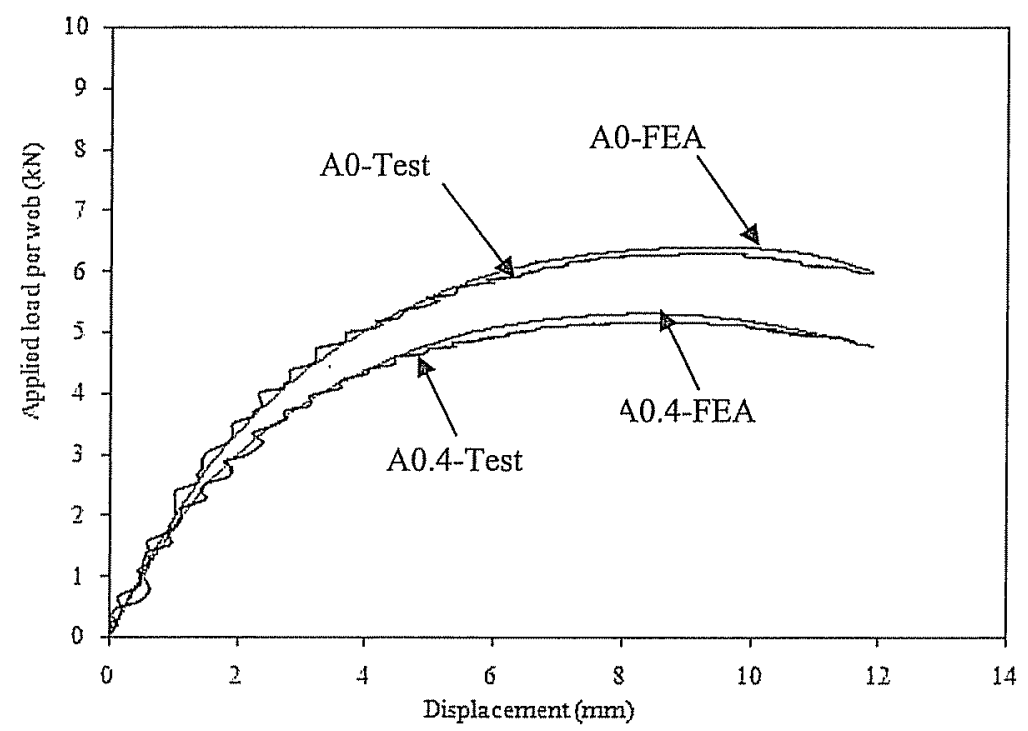

Figure 6: Comparison of web deformation curves for specimen 172-N65 
Table 2: Measured specimen dimensions and comparison of the web crippling strength predicted from the $\mathbb{F E A}$ with the experiment results

\begin{tabular}{|c|c|c|c|c|c|c|c|c|c|c|}
\hline Specimen & Web & Flange & Lip & $\begin{array}{l}\text { Thick } \\
\text {-ness }\end{array}$ & Fillet & Holes & Length & $\begin{array}{l}\text { Exp. } \\
\text { Load }\end{array}$ & $\begin{array}{l}\text { FEA } \\
\text { Load }\end{array}$ & $P_{\operatorname{EXP}} /$ \\
\hline & $d$ & $b_{f}$ & $b_{l}$ & $t$ & $r_{i}$ & $a$ & $L$ & $P_{\mathrm{EXP}}$ & $P_{\mathrm{FEA}}$ & \\
\hline & $(\mathrm{mm})$ & $(\mathbf{m m})$ & $(\mathbf{m m})$ & $(\mathbf{m m})$ & $(\mathrm{mm})$ & $(\mathbf{m m})$ & $(\mathbf{m m})$ & $(\mathrm{kN})$ & $(\mathrm{kN})$ & \\
\hline $142-\mathrm{N} 30 \mathrm{A0}$ & 142.9 & 59.0 & 15.2 & 1.21 & 4.8 & 0.0 & 501.0 & 5.6 & 5.5 & 1.02 \\
\hline $142-\mathrm{N} 30 \mathrm{~A} 0.4$ & 144.6 & 57.0 & 15.4 & 1.22 & 4.8 & 55.2 & 502.7 & 4.5 & 4.3 & 1.03 \\
\hline 142-N60A0 & 142.4 & 60.0 & 16.0 & 1.21 & 4.8 & 0.0 & 551.3 & 6.0 & 5.9 & 1.02 \\
\hline $142-\mathrm{N} 60 \mathrm{~A} 0.4$ & 142.5 & 59.8 & 14.5 & 1.20 & 4.8 & 54.8 & 550.9 & 4.9 & 4.7 & 1.06 \\
\hline 172-N32.5A0 & 172.7 & 64.8 & 14.9 & 1.23 & 4.8 & 0.0 & 599.9 & 5.7 & 5.6 & 1.02 \\
\hline $172-N 32.5 \mathrm{~A} 0.4$ & 172.7 & 64.3 & 14.9 & 1.24 & 4.8 & 67.1 & 606.8 & 4.6 & 4.6 & 0.98 \\
\hline 172-N65A0 & 172.8 & 64.0 & 14.8 & 1.26 & 4.8 & 0.0 & 649.8 & 6.3 & 6.4 & 0.98 \\
\hline 172-N65A0.4 & 173.0 & 64.3 & 14.9 & 1.27 & 4.8 & 67.0 & 650.9 & 5.2 & 5.3 & 0.97 \\
\hline 202-N32.5A0 & 202.5 & 63.6 & 16.0 & 1.40 & 4.8 & 0.0 & 678.3 & 6.8 & 6.9 & 0.99 \\
\hline $202-\mathrm{N} 32.5 \mathrm{~A} 0.4$ & 202.3 & 64.0 & 15.3 & 1.44 & 4.8 & 79.1 & 675.6 & 5.6 & 5.9 & 0.96 \\
\hline 202-N65A0 & 202.5 & 64.0 & 17.5 & 1.44 & 4.8 & 0.0 & 701.0 & 7.4 & 7.7 & 0.96 \\
\hline 202-N65A0.4 & 202.4 & 63.9 & 17.0 & 1.39 & 4.8 & 79.1 & 701.4 & 5.8 & 5.6 & 1.03 \\
\hline 262-N32.5A0 & 262.6 & 64.6 & 15.8 & 1.48 & 5.5 & 0.0 & 850.5 & 6.6 & 6.5 & 1.01 \\
\hline $262-N 32.5 \mathrm{~A} 0.4$ & 263.4 & 63.4 & 14.4 & 1.52 & 5.0 & 102.5 & 836.0 & 5.3 & 5.5 & 0.96 \\
\hline 262-N65A0 & 263.1 & 65.9 & 15.1 & 1.54 & 5.0 & 0.0 & 907.3 & 7.7 & 7.8 & 0.99 \\
\hline 262-N65A0.4 & 262.5 & 63.8 & 14.4 & 1.47 & 5.5 & 102.5 & 896.7 & 5.5 & 5.4 & 1.02 \\
\hline 302-N44A0.4 & 304.0 & 87.9 & 18.0 & 1.93 & 4.8 & 118.2 & 998.9 & 10.2 & 9.9 & 1.03 \\
\hline 302-N90A0 & 303.8 & 88.8 & 18.7 & 1.96 & 4.8 & 0.0 & 1052.2 & 14.1 & 13.5 & 1.04 \\
\hline 302-N90A0.4 & 303.1 & 87.8 & 19.1 & 1.94 & 4.8 & 118.0 & 1050.9 & 11.3 & 10.7 & 1.06 \\
\hline \multicolumn{10}{|l|}{ Mean } & 1.01 \\
\hline \multicolumn{10}{|l|}{ COV } & 0.03 \\
\hline
\end{tabular}

A comparison of the test results $\left(P_{\mathrm{EXP}}\right)$ with the numerical results $\left(P_{\mathrm{FEA}}\right)$ of web crippling strengths per web is shown in Table 2 . Load-deflection curves comparing the experimental results and the FE results are shown in Fig. 6 covering the cases of both with and without the 
web holes. It can be seen that good agreement has been achieved between both results for all specimens. The mean value of the $P_{\mathrm{EXP}} / P_{\text {FEA }}$ ratio is 1.01 with the corresponding coefficient of variation (COV) of 0.03 . A maximum difference of $6 \%$ was observed between the experimental and the numerical results for the specimen 142-N60A0. Considering onequarter set up, the web crippling failure mode observed from the tests has been also verified by FE model for the ITF loading conditions, as shown in Fig. 5.

\section{Conclusions}

An experimental and numerical investigation of lipped channel sections with and without circular web holes subjected to web crippling have been presented. A series of tests was conducted on lipped channel sections with web holes subjected to the ITF loading condition. The web slenderness value of the specimens ranged from 116 to 176 . A FE model that incorporated the geometric and the material nonlinearities has been developed and verified against the experimental results. The FE model was shown to be able to closely predict the web crippling behaviour of the channel sections, both with and without circular web hole. The new web crippling test data presented in this paper can be used to develop design rules for cold-formed steel sections.

\section{References}

[1] J. Rhodes and D. Nash (1998), An investigation of web crushing behaviour in thin-walled beams, ThinWalled Structures, Vol. 32, pp.207-230.

[2] W.W. Yu and C.S. Davis (1973), Cold-formed steel members with perforated elements, Journal of the Structural Division, Vol. 99, pp. 2061-2077.

[3] K.S. Sivakumaran and K.M. Zielonka (1989), Web crippling strength of thin-walled steel members with web opening, Thin-Walled Structures, Vol. 8, pp.295-319.

[4] R.A. LaBoube, W.W. Yu, S.U. Deshmukh and C.A. Uphoff (1999), Crippling Capacity of Web Elements with Openings, Journal of Structural Engineering, Vol. 125, pp.137-141.

[5] J.E. Langan, R.A. LaBoube and W.W. Yu (1994), Structural behavior of perforated web elements of coldformed steel flexural members subjected to web crippling and a combination of web crippling and bending, in: Final Report,Civil Engineering Series 94-3,Cold-Formed Steel Series, University of Missouri-Rolla, Rolla, USA.

[6] F. Zhou and B. Young (2010), Web crippling of aluminum tubes with perforated webs, Engineering Structures, Vol. 32,pp.1397-1410.

[7] NAS (2007), North American Specification for the Design of Cold-Formed Steel Structural Members, American Iron and Steel Insititute, AISI Standard.

[8] ANSYS (2011), User's manual, revision 11.0, in, Swanson Analysis System.

[9] EN, 10002-1: 2001 (2001),Tensile testing of metallic materials. Method of test at ambient temperature, British Standards Institution. 
Proceedings of the $10^{\text {th }}$ International Conference on Advances in

Steel Concrete Composite and Hybrid Structures

Editors

IY Richard Liew and Siew Chin Lee

Department of Civil E Environmental Engineering

National University of Singapore, Singapore 
Published by

\section{Research Publishing}

No: 83 Genting Lane, \#08-01 Genting Building, 349568 SINGAPORE.

India Office: New No: 61/1 First Cross Street, CIT Nagar, Chennai 600035.

e-mail: editorial@rpsonline.com.sg

Proceedings of the 10th International Conference on

ADVANCES IN STEEL CONCRETE COMPOSITE AND HYBRID STRUCTURES

Edited by J Y Richard Liew and Siew Chin Lee

Copyright (C) 2012 Research Publishing Services. All rights reserved.

This book, or parts thereof, may not be reproduced in any form or by any means, electronic or mechanical, including photocopying, recording or any information storage and retrieval system now known or to be invented, without written permission from the Publisher.

All the papers in this volume have been peer-reviewed. However, the editor assume no responsibility for the accuracy, completeness or usefulness of the information provided in this proceedings. No responsibility is assumed by the publisher or editor for any use or operation of any methods, products, instructions or ideas contained in the materials presented.

\section{Disclaimer:}

No responsibility is assumed by the ASCCS 2012 Organizers/Publisher for any injury and/or damage to persons or property as a matter of products liability, negligence or otherwise, or from any use or operation of any methods, products or ideas contained in the material herein. Contents, used in the papers are how it is submitted by the contributors after minor changes in the formatting. Whilst every attempt made to ensure that all aspects of the papers are uniform in style, the ASCCS 2012 Organizers, Publisher or the Editor(s) will not be responsible whatsoever for the accuracy, correctness or representations of any statements or documents presented in the papers.

ISBN-13: 978-981-07-2615-7

ISBN-10: 981-07-2615-5

Design, Typeset \& Printed by iTEK CMS Web Solutions. e-mail:enquiries@itekcms.com

Printed in Singapore. 